\section{RÉSUMÉ}

\section{In the air}

ASTUTE seismologists may be able to hear distant volcanic eruptions, H. Kanamori and J. Mori have discovered (Geophys. Res. Lett. 19, 721-724; 1992). The authors suggest that atmospheric waves set up by the eruption at Pinatubo were responsible for a puzzling, two-hour seismic rumble recorded worldwide on 15 June last year. The signal was weak, but the authors identified a strong component with a period of 228 seconds - far too long to be associated with any activity in the volcano's magma chamber. But there are atmospheric oscillations with natural periods around 250 seconds which could have been set up by heat from the eruption. Indeed, a contemporary satellite image of Pinatubo and its environs shows a temperature anomaly extending over $300 \mathrm{~km}$ from the volcano, completing the authors' argument. The result was a remarkable cycle of excitation - from land to atmosphere and back to land.

\section{Vampire wedding}

DURING development of the Drosophila retina, formation of the $\mathrm{R} 7$ photoreceptor neuron is induced by contact with its neighbour R8. The process is mediated by the interaction of the cell-surface tyrosine kinase sevenless (sev), expressed on all the photoreceptors, and its R8-specific ligand bride of sevenless (boss). R. L. Cagan et al. (Cell 69, 393-399; 1992) have used antibodies to different regions of boss to examine its fate after contact with sev. Remarkably, although boss is thought to contain no fewer than seven membrane-crossing helices, they find that the entire protein is taken up together with sev by the nascent R7 cell. The authors speculate that this may occur by receptor-mediated endocytosis of small patches of R8 membrane, although they cannot rule out other possibilities.

\section{Enigma variations}

COMPUTER reconstructions of a flawless Sphinx of Giza preside over a paper by $M$. Lehner in the Cambridge

Archaeological Journal (2, 3-26; 1992).

The monument was carved from solid limestone 4,600 years ago. It then fell prey to robbers and the ravages of shifting sands, until restoration and further adornment in the 18th dynasty 1,200 years later. Millennia of neglect then ensued. The images of the restored, 18th dynasty Sphinx complete with beard, cobra symbol and chest statue - are the upshot of a four-year programme which resulted in a full set of contoured, scale drawings of the monument, then transformed into three-dimensions by computer graphics. The reborn Sphinx will no doubt be appearing on theme-park screens before too long.

\title{
In the pink (and yellow)
}

\section{Jeremy J. D. Greenwood}

'SMALL science' is alive and well, as a paper on the land snail Cepaea hortensis in the latest issue of Proceedings of the Royal Society ${ }^{1}$ shows. Armed with little more than polythene bags, notebook and calculator, Robert Cameron has made a notable contribution to a long-standing debate in evolutionary genetics.

Cepaea nemoralis and $C$. hortensis are classic subjects of study. They display genetic polymorphisms for both the colour and the banding patterns of their shells, and there has been intense debate over the relative importance of natural selection and of random genetic drift in maintaining the polymorphism and in determining the morph-frequency differences between populations. As so often, a problem has been that selective forces may be powerful enough to override random events and yet have such subtle effects that they cannot be detected. But by use of a particularly well-focused sampling programme, Cameron has been able to establish morph-frequency changes of only a few per cent and to show that the changes are almost certainly associated with selection.

In cloudless weather, the ground in open countryside cools rapidly after sunset because of radiative heat loss to the sky. Cool air near the ground surface flows downslope and may accumulate in valley bottoms, which may as a result become many degrees cooler than the nearby valley sides. A quarter of a century ago, Cameron surveyed $C$. hortensis populations in a $10 \times 10 \mathrm{~km}$ area in south-east England, in a region of chalk hills with such strongly incised topography that many of the valley bottoms are notorious frost hollows. There he found that the snail populations of valley bottoms tended to have higher frequencies of yellow shells than those on valley sides. This, and similar evidence from elsewhere, fits in with experimental evidence that snails with yellow shells are more resistant to cold than are those with pink shells ${ }^{2-4}$. Broad geographical patterns of the distribution of yellows also fit in with this conclusion $^{2-4}$.

Cameron's original study took place shortly after a particularly cold, anticyclonic winter, when selection favouring yellow shells in valley bottoms must have been particularly intense. Since then, winters have been milder and Cameron surmised that the selection favouring yellow shells in valley bottoms should have been generally weaker. $\mathrm{He}$ therefore returned to the area and resampled as many of the $C$. hortensis populations as possible, carefully return- ing to within a few metres of his original sampling sites. A number of populations had become extinct because of roadbuilding and similar activities. In some places morph-frequencies had altered so much that the changes were statistically significant even at a single site. Such large changes were always associated with marked alterations in the habitat.

Because his original survey had shown that morph-frequencies were associated not only with topography but also with habitat (in a way consistent with the classic effects of selection by visual predators ${ }^{5}$ ), Cameron excluded these sites from further analyses. At the remaining sites, there was a clear pattern: although morph-frequencies had not changed significantly at any of the individual sites, there was a significantly consistent trend for the frequency of yellows to have dropped in valleybottom sites between the two surveys but no general trend in sites on valley sides. This accords exactly with expectations based on the hypothesis that the excess of yellows in the valley-bottom sites in 1964-66 was largely a result of the unusually severe winter of 1962-63, because it is in valley bottoms that cold air settles. The subsequent milder winters have not, on average, favoured yellows so strongly in valley bottoms.

The gene-frequency change detected by Cameron is, by normal standards, minute: the mean frequency of the yellow allele in the area was 87.7 per cent in 1964-66 and 85.9 per cent in 1990 . That he was able not only to detect it but also convincingly to ascribe it to a particular cause is because he concentrated on individual sites, not only relocating his original sample sites carefully but also taking into account that sites differed in the extent to which they would be expected to show morph-frequency changes. The study demonstrates the over-riding value in ecology of a sound knowledge of the organism on which one works, of having a clear focus to one's investigation, and (not least) of long-term thinking and meticulous fieldwork.

Jeremy J. D. Greenwood is at the British Trust for Ornithology, Thetford, Norfolk IP24 2PU, UK.

\footnotetext{
1. Cameron, R. A. D Proc, R. Soc B248, 181 187 (1992)

2. Jones, J. S. Leith, B. H. \& Rawings, P. A. Rev. Ecol. Syst. 8, 109-143 (1977)

3. Clarke, B., Arthur, W.. Horsiey, D. T. \& Parkin, D. T. in Pulmonates Vol. 2 A (eds Fretter, V. \& Peake, J. F.) 219-270 (Academic, New York, 1978).

4. Cain, A. J. in The Mollusca Vol. 6 (ed. Russell-Hunter. W. D.) 597-647 (Academic, London, 1983)

5. Cain, A. J. \& Sheppard, P. M. Genetics 39, 89-116 (1954).
}

(๖) 1992 Nature Publishing Group 